\title{
Successful Practices in Customer Relationship Management
}

\author{
Rainer Alt, Thomas Puschmann \\ Institute of Information Management \\ University of St. Gallen \\ St. Gallen, Switzerland \\ \{Prename.Surname\}@unisg.ch
}

\begin{abstract}
Many companies have initiated projects to improve on customer orientation and plan the implementation of customer relationship management (CRM) systems. Among the desired benefits are increased customer satisfaction and retention by providing personalized products and value added services. Although the potentials of CRM are obvious only a few successful CRM implementations are known in practice. This article describes the results of a cross-industry benchmarking project in which 120 companies participated. The results show that there is no 'unique' CRM project and that successful implementations are rarely technical projects. From the research six critical success factors for CRM projects emerged: stepwise evolution, straightforward implementation and longterm project, organizational redesign, integrated system architecture of standard components, change management, and top management support. The six successful practice companies show examples of how these critical success factors are applied.
\end{abstract}

\section{Introduction}

Building and maintaining customer relationships is neither new nor necessary tied to the use of information technology. Nonetheless, the use of customer relationship management (CRM) systems is becoming increasingly important to improve customer lifetime value [33]. By providing information on customer data, profiles and history they support an important area of a company's core processes, especially in marketing, sales and service [7], [15]. In fact, the adoption of CRM systems leads to a redesign customer oriented processes, similar to the effect which ERP systems have had on production-oriented processes. In spite of the wide use of sales force automation systems in sales [20] a Forrester study [4] observes significant deficits in today's marketing, sales and service processes. It was found that just $22 \%$ of the companies surveyed possess a uniform customer view and only $37 \%$ know which customers are looked after by the individual business units. A customer profiling concept for customer selection is used by just $19 \%$ of the companies surveyed and only $20 \%$ know whether a customer has visited their internet portal.

To eliminate weaknesses in customer contact, many companies are either planning or in the process of implementing CRM systems. According to a Gartner survey [8] $65 \%$ of US companies intended to initiate CRM projects in 2002 (see also [21] and [1]). In Europe, roughly 3\% of companies had fully implemented a CRM project in 2001, $17 \%$ had initiated more than one local project and $35 \%$ were developing concepts for the introduction of CRM [27]. Another 45\% have not pursued any CRM activities to date.

As Wayland/Cole [29] point out, CRM projects have new implementation qualities which may also be connected with the high number of failed CRM projects [24]. Our research aims to establish an understanding what businesses are doing in the area of CRM and to identify factors which determine the success of CRM projects. For this purpose a consortium was established which performed a benchmarking project consisting of questionnaires, interviews and site visits. Section 2 describes the research method and the six successful practice companies. Section 3 provides the results of the CRM benchmarking project based on five benchmarks. Finally, Section 4 derives six generic success factors and presents an outlook into future CRM developments.

\section{Research Method}

\subsection{Literature Review}

The first requirement for the successful implementation of CRM is clarity regarding CRM terminology. From the many approaches available, the distinction between the following three areas has become generally accepted [6]:

- Operational CRM supports front office processes, e.g. the staff in a call center [28],[17], [5], [9].

- Analytical CRM builds on operational CRM and establishes information on customer segments, behavior and value using statistical methods [18], [19]. 
- Collaborative CRM concentrates on customer integration using a coordinated mix of interaction channels (multi-channel management), e.g. online shops, and call centers [12].

CRM is therefore understood as a customer-oriented management approach where information systems provide information to support operational, analytical and collaborative CRM processes and thus contribute to customer profitability and retention.

Research on success factors is an area that has already received some attention in the IS literature. Among the examples is the general taxonomy of Williams/Ramaprasad [31] and the increasing interest in factors that determine the success of E-Commerce or Webpresences [26]. Although CRM is often conceived as part of E-Commerce [23], Wilson et al. [32] report success factors which are specific to CRM projects. Using the induction method they discovered the need for project approval procedures, the need to leverage best practices, the importance of prototyping new processes, and the need to manage for the delivery of the intended benefits. Based on the work of Wells et al. [30], Bose [2] describes more specific critical issues that need to be addressed during the CRM development life-cycle. Among the recommendations are to conduct a complete business analysis since CRM implies changes along interaction points with customers, to ensure long-term commitment of senior level management, to consider a stage-wise implementation of the CRM-modules, and to carefully address 'people problems' during the implementation process. In a study of 96 organizations, $\mathrm{Yu}$ [34] reports that corporate culture and process and technology improvement were the "best predictors of CRM success".

\subsection{Benchmarking Procedure}

To investigate the use of CRM in organizations and to identify successful practices the criteria provided by existing research were applied in a benchmarking procedure. This approach has proved suitable for obtaining information on current practices and results [16]. Benchmarking which foresees the systematic comparison of and learning from other organizations may differ in many dimensions, such as internal/external and qualitative/quantitative design [3]. The external and qualitative consortium benchmarking approach adopted here comprised customer relationship executives from 12 organizations and 4 researchers. Due to the chosen research methodology - a mix of questionnaire and case study approach - this research presents a broad and in-depth picture of CRM. Four phases were completed within the timeframe May through September 2001 (see Figure 1):

- Preparation and kick-off meeting. The research team outlined the topic and goals of the benchmarking project and established the consortium. Based on litera- ture introduction project, CRM organization and processes, system architecture, efficiency, and culture have been selected as benchmarks and refined as criteria during the kick-off meeting (see Table 1).

\begin{tabular}{|c|c|}
\hline Benchmarks & Criteria \\
\hline $\begin{array}{l}\text { Introduction } \\
\text { project }\end{array}$ & $\begin{array}{l}\text { - High level of implementation } \\
\text { - Running CRM system (> } 6 \text { months) }\end{array}$ \\
\hline $\begin{array}{l}\text { Organization } \\
\text { and customer } \\
\text { process }\end{array}$ & $\begin{array}{l}\text { - Customer process thinking } \\
\text { - Analytical CRM (customer segmentation) } \\
\text { - Customer centred organization structures }\end{array}$ \\
\hline $\begin{array}{l}\text { System } \\
\text { architecture }\end{array}$ & $\begin{array}{l}\text { - Centralized customer database } \\
\text { - Integration of CRM applications } \\
\text { - Integration of Internet portals } \\
\end{array}$ \\
\hline Efficiency & $\begin{array}{l}\text { - Quantification of CRM effects } \\
\text { - Availability of measurement system }\end{array}$ \\
\hline Culture & $\begin{array}{l}\text { - } \text { CRM as corporate philosophy } \\
\text { - Availability of change management }\end{array}$ \\
\hline
\end{tabular}

Table 1. Benchmarks and criteria

- $\quad$ Screening phase. The research team identified 200 potential successful practice organizations of which 120 received questionnaires structured according to the benchmarking criteria defined in the kick-off meeting. Out of the 55 returned questionnaires 13 structured telephone interviews and 10 in-depth case studies were selected.

- Review meeting. At the second consortium meeting the research team presented the questionnaire results and the case studies on an anonymous basis. These were then analyzed and evaluated by the consortium members who finally selected 6 companies as successful practices.

- Company visits and final conference. The research team and the consortium members visited the successful practice organizations, spending one day at each company. The results of the evaluation were presented to the consortium at the final conference.

The design of the research project provided two data sources for evaluation purposes: 1) the 55 questionnaires returned, which originated primarily from European companies (59\%) with over 50,000 employees (48\%), and 2) the six comprehensive case studies recorded on site at the successful practice organizations. Both sources are described in detail in the following sections. 


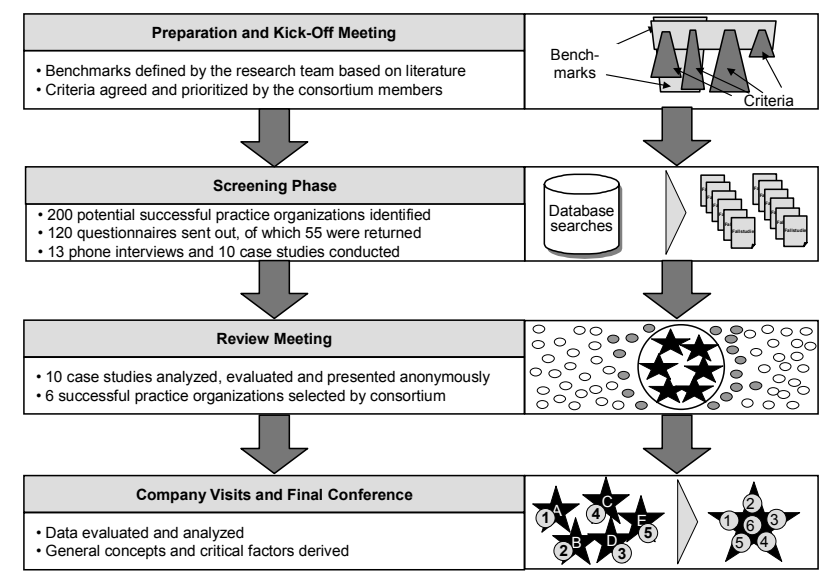

Figure 1. Steps in the CRM consortium benchmarking

\subsection{Successful Practice Organizations}

The successful practice organizations which were selected during the review meeting consisted of the following:

- Alta Resources Corp. in Neenah (WI), USA, a service provider in the area of call centers and customer interaction (e.g. complaint management, lead generation). As early as 1995 Alta Resources implemented a Vantive system for managing the customer contacts of all clients by telephone, e-mail, letter and internet portals.

- Bertelsmann AG in Gütersloh, Germany, whose Direct Group is responsible for the relationships to approx. 20 million book club and online customers worldwide. With its subsidiary Syskoplan the company set up a 'Market Intelligence Organization' in 1996 and implemented an integrated SAP system with the modules CRM, APO, BW and PS.

- Consors Discount-Broker AG in Nuremberg, Germany, a financial services provider focusing on internet-based securities transactions. Consors handles interactions to its 450,000 customers primarily via their call center and internet portal. In October 2000 the company began with the introduction of an integrated Clarify system.

- Heidelberger Druckmaschinen $A G$ in Heidelberg, Germany, an international supplier of printing solutions who aimed to improve the contact and direct sales to their 100 ' 000 customers worldwide. Starting in 1996 Heidelberg designed a CRM strategy which also includes the implementation of a centralized Clarify system.
- Swisscom AG in Zurich, Switzerland, reorganized its customer contacts in 1998. With a Direct Marketing Center (DMC) the company has created two corporate areas which have been supported by a Vantive system for customer contact management since 1999. It handles 6 million telephone calls per annum, 1.5 million incoming and 2 million outgoing letters.

- Unisys (Schweiz) AG in Thalwil, Switzerland, a subsidiary of the Unisys Corporation in Blue Bell, Philadelphia, USA, supplies IT-services to about 220 customers. Following a reorganization of its sales structure at the end of the 1990s, the company introduced a Siebel system which provides uniform customer data for sales, reporting and forecasting at a global level.

\section{Benchmarking Results}

\subsection{Introduction Project}

Almost all of the 55 companies who returned the questionnaires mentioned a similar set of motivations for the initiation of their CRM activities. Among the examples are improved customer selection, the targeted use of channels for customer contact, enhanced customer value through cross-and up-selling opportunities and increased transparency in CRM processes. Only $11 \%$ of the companies stated efficiency as a major motivator for CRM.

The strategic nature of CRM is also reflected in the implementation projects which typically begin with coordination between the areas marketing, sales/distribution and IT, and the definition of common goals. In $80 \%$ of the organizations surveyed, an overall concept formed the starting point for the introduction of CRM, which in 64\% of cases was coordinated with an E-business strategy and the reorganization of business processes (44\%). At Heidelberg CRM was part of a corporate eBusiness project called e-Forum which defined transformation maps and standards for $\mathrm{R} \& \mathrm{D}$, finance and production, administration and marketing, sales and after sales. In the latter, CRM comprised 10 customer focused projects which were offered as pre-configured solutions to the country organizations.

An important part of the introduction projects was the implementation of the CRM-system. This phase was completed in an average of 7 months and included the definition of evaluation criteria, the software selection, customizing, pilot and roll-out. $67 \%$ of all companies implemented a pilot application before rolling out the system. Similar evaluation criteria were used in each case: in addition to manufacturer-related criteria such as manufacturer's vision, support and globality, importance was attached above all to product-related characteristics such as 
functionality, product maturity, integration capability and modularity of the solution.

In all the organizations considered, project coordination was handled centrally, while less than one third of CRM projects were in the responsibility of the IT department. As Figure 2 shows, marketing, sales/distribution and management were frequently involved in the projects.

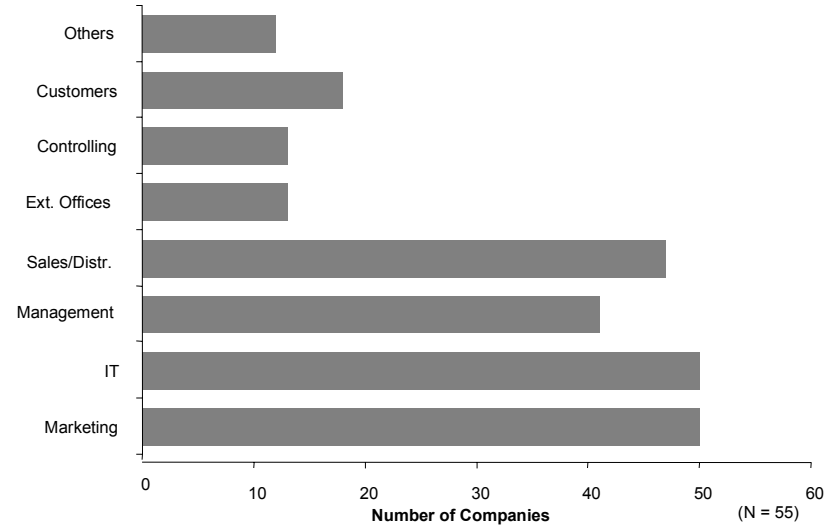

Figure 2. Departments involved in CRM implementation projects

\subsection{CRM Organization and Processes}

The benchmarking showed that CRM involves significant changes regarding the organization of marketing, sales and service activities. Most companies reorganized internal processes and implemented them on a crossfunctional and cross-organizational basis (see Figure 2). Remarkably, only $30 \%$ involved the customers themselves in the design process. More information in redesign efforts were provided by the six successful practice companies:

- Customer life cycle models. Customer relationships are divided in various phases and individual services are offered to the customer in each phase. For example, customers in the service phase at Heidelberg may obtain information and spare parts through their online shop. Companies such as Consors and Swisscom link analytical CRM processes to the operational activities. The life cycle is used to predict customer behavior, e.g. when a customer can be addressed via a campaign, when he or she is likely to cancel a relationship etc. Customers are assigned based on past purchases, volumes, and socio-demographic or geographical data.

- Customer segmentation. Responsibility for customers has been redesigned on the basis of customer and/or market segments. For example, a board member at Consors has responsibility for large volume customers ('heavy traders') across the company's entire product portfolio. Unisys (Switzerland), is now organized according to 'Financial Industries' and Swisscom according to 'Fixnet' and 'Mobile' customers.

- Centralized organization units. Responsibility for CRM activities is usually organized in new organizational units which act as internal service providers. Heidelberg covers local markets with 85 Sales and Service Units (SSU) who provide the business areas with marketing tools, know-how and experience. A new department 'Marketing Intelligence \& CRM' (MI-M) coordinates marketing activities and utilizes synergies on a corporate basis. Bertelsmann, Swisscom, and Consors have also established corporate centers which offer specialist skills and know-how in the area of analytical CRM (e.g. churn analyses, data mining).

- Link to forecasting. Information from operational CRM processes is used in predicting sales volumes and supply chain planning. Unisys implemented a fortnightly evaluation of opportunities which led to a maximum sales forecasting variance of $+/-2 \%$. Bertelsmann uses the planned campaign successes for requirements planning in the supply chain to their book stores, e.g. a campaign success of $15 \%$ leads to an equivalent increase in the demand of books.

Centralization of CRM responsibility proved important for achieving the necessary standardization of CRM activities. Unisys (Switzerland) had already adapted a global standardized sales process which ensured a uniform understanding of the terms 'lead', 'opportunity', 'quotation', etc. Standardized interfaces between complaints and service management enabled the integration of two formerly separate processes. Heidelberg's service engineers, for example, now know when a production manager is planning to buy a new machine.

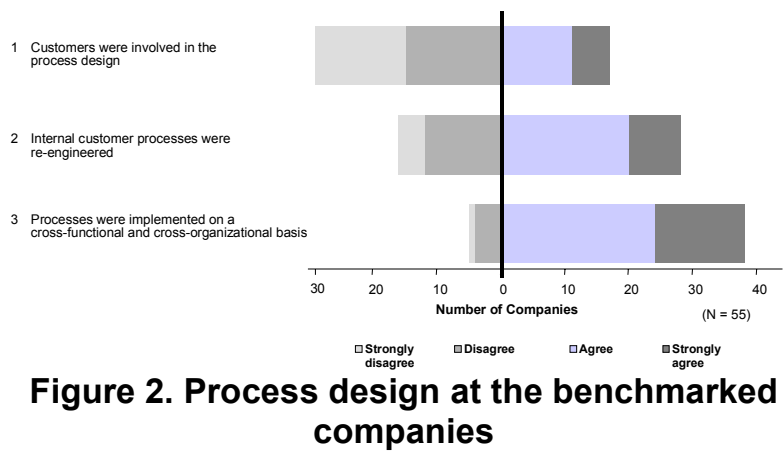




\subsection{System Architecture}

CRM systems usually replace isolated solutions which support specific activities in marketing, sales, and service. A centralized database provides a uniform view of customers and support for standardized processes. Although $58 \%$ of all companies said they had a CRM system in operation, less than half of them used it on a crossorganizational basis. As Figure 3 shows, almost all companies pursue a best-of-breed approach, i.e. specialized systems from Siebel, Vantive, Update or Clarify complement existing ERP systems. Four companies, including Bertelsmann, use SAP CRM linked with other SAP components. Although similar in their basic functionalities, the system decisions reflect each vendors strengths: sales force support at Siebel, service and call center support at Vantive and Clarify, and integrated processes at SAP. Most companies customized the selected systems to suit their individual requirements. At Heidelberg the MI-M department defined three reference models for a global standard functionality together with the local SSUs and customized roughly $20 \%$ at local level. This ratio was also observed at the other successful practice organizations $(20-30 \%)$.

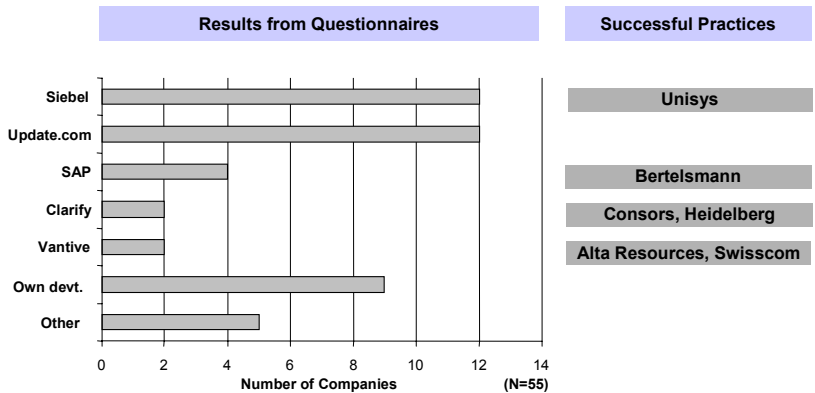

Figure 3: CRM systems used by benchmarking participants

Many companies had a centralized system architecture. Globally operating companies, such as Bertelsmann, Heidelberg, and Unisys, had local systems with periodically replicating customer databases. These architectures also provided integration across different CRM dimensions:

- Operational CRM. Operational integration points exist to human resource systems for user data and ERP systems for transferring order information which was captured e.g. from a call center representative. Integration to supply chain systems is illustrated by Bertelsmann: Campaign data from SAP CRM is sent to SAP SD for the calculation of sales plan data, and then routed to SAP MRP for requirements and procurement planning. 'Anomalies', i.e. products where inventories remain significantly above or below demand, are shown in the SAP APO Alert Monitor.
- Analytical CRM. For management and evaluation purposes, the operational customer data are integrated with a centralized data warehouse which consolidated data based on certain criteria (e.g. sales, profits) in a uniform data model. Consors, for example, has stored all 30 million transactions performed to date. A customer's transactions can be analyzed over time, e.g. all customers who opened a securities account in 1997/98 and since then have only carried out 1-5 transactions. The data mining tool analyzes defined dimensions, e.g. compares the characteristics of one building loan customer with another, leading to the determination of a customer segment with an 'affinity' for building loans and thus providing the basis for a targeted marketing campaign.

- Collaborative CRM. Approximately $60 \%$ of the companies surveyed use internet portals in their customer communication (see Figure 4) for selected or suitable activities. Heidelberg, for example, offers the sale of some consumer goods (e.g. printing cartridges) and service management. At Alta Resources a green light in the Vantive system alerts the call center representative that personal data has been entered in a customer's portal and that the customer requires further information on a specific product. Consors also has a distinctive collaborative CRM system which handles customer transactions both through the call center and via the portal. The latter also features complementary services such as insurance.

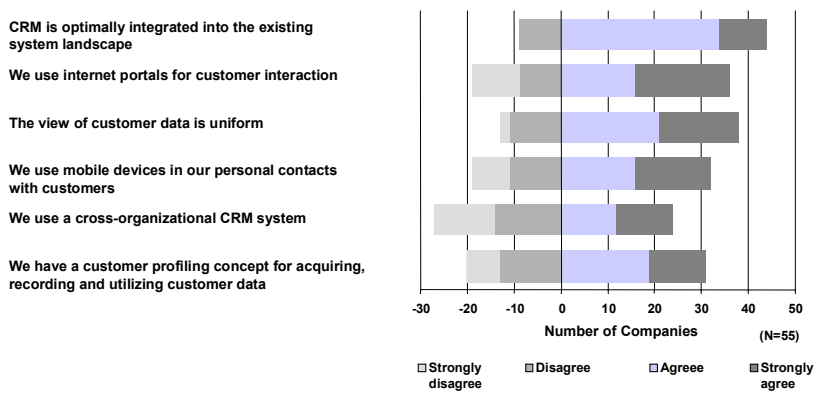

Figure 4. Questionnaire results on system architecture

\subsection{Operational Efficiency}

Implementing a CRM system is not mainly driven by the possible savings. $55 \%$ of the benchmarked companies agreed that strategic or qualitative goals have been the main drivers for introducing CRM. Among the effects are improved process and data transparency, better customer retention, higher consultancy quality, more targeted customer communication or proactive customer management. Only $38 \%$ have proved the operational efficiency com- 
pared to $50 \%$ which reported difficulty in measuring CRM effects. Figure 5 summarizes the most frequently used benefit arguments.

Among the successful practices, Swisscom performed an operational efficiency analysis composed of direct effects (savings relating to operational processes in direct marketing and data maintenance), indirect effects (fewer misses, greater productivity in sales), increased sales volume and additional business which led to a ROI of 2.9 years for the CRM project. At Consors, qualitative goals such as improved customer service were the clear priority, but have been supported by a thorough control of timeframe and budget, as well as by process savings of $30 \%$ and increased revenues of $40 \%$. Both figures were detailed, e.g. process savings with reduced postage costs due to more focused mailings (from 500,000 to 1,000 letters per mass mailing).

Heidelberg calculated a positive net present value which also included the corporate standardization of CRM systems (cost-effective rollout, release change, etc.). Bertelsmann expects improved customer care for their 20 million club customers and is trying to increase the success rate of campaigns through more targeted customer communication. Purely qualitative arguments were mentioned at Unisys, e.g. the strategic necessity of systematic opportunity management with key accounts.

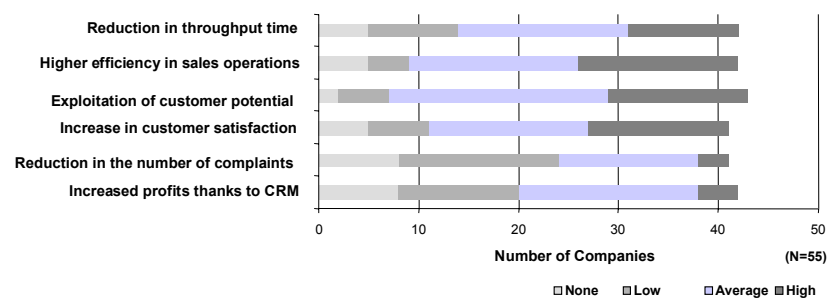

Figure 5. Potentials of CRM projects

\subsection{Culture}

Involving as many potential system users as possible is vital to the adoption of CRM within an organization. This not only refers to establish the necessary skills for operating the system but also to convince staff that the system will be beneficial. In all benchmarked companies management played an active role in the decision-making process and the implementation of CRM (see Figure 6). Other departments involved included marketing, customer contact centers, finance and/or accounting, sales and technical service, and seldom logistics and production.

Although most CRM projects were within time and budget, the effort to obtain adoption varied. In call center implementations (Swisscom, Consors, Alta Resources, Bertelsmann) employee acceptance largely existed. At Bertelsmann, the call center staff were involved in the CRM design and were able to relate to the goals of CRM (better call center support, no loss of jobs) from the out- set. Heidelberg and Unisys used a similar strategy to convince field sales force who consider their knowledge of customers and markets to be personal advantages and therefore find it difficult to share it throughout the company. Heidelberg's goal was to shape an understanding that CRM is about 'a transparent customer, not about transparent salesmen'. At Unisys all staff were trained and obliged to use the system. Despite organizational rules (no budget without system entry) motivated users, some users had to be 'motivated' with pressure and some non-users were observed after two years. Unisys and Heidelberg estimate a minimum of two years for filling the database with the customer data. Use of the systems by management was considered as a motivating boundary condition.

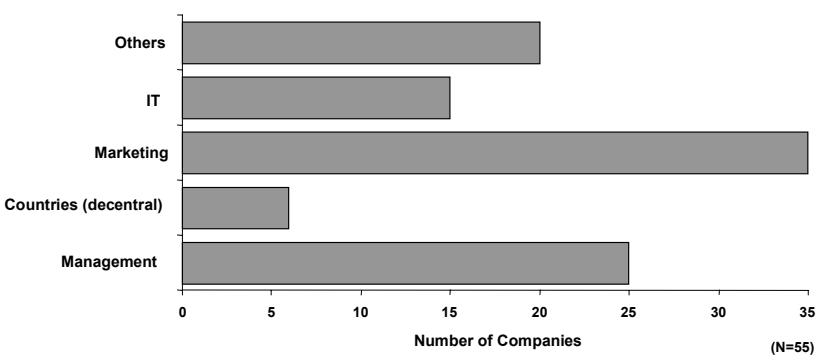

Figure 6. Organizational units responsible for CRM

\section{Success Factors and Outlook}

\subsection{Success Factors in CRM}

The benchmarking consortium detailed and prioritized measurements for each benchmark identified in the kickoff meeting (see Table 1) and guided the entire selection of successful practices. Our analysis led to the formulation of six success factors (see Table 2). They support existing findings regarding non-technical factors in IT adoption (e.g. [2], [14], [15], [22], [32], [34]). Although the implementation of a CRM system often marks the start of a company's reorganization in marketing, sales and service, the success is mainly determined on organizational and cultural turf:

- Evolution path. As a first step, most companies implemented a system for operational CRM, e.g. call center or sales force processes. This corresponds to existing research which considers a centralized database providing consistent and up-to-date information as a prerequisite for CRM [15]. Analytical CRM rests upon this foundation and covers data mining and churn analysis functionality. Only little use was made of collaborative CRM which indicates an evolution 
path from operational, analytical to collaborative CRM and a stepwise implementation of CRM.

- Timeframe. Most successful practice organizations have gone through a rapid system evaluation phase and completed the system introduction phase within approximately 7 months. However, filling the database with meaningful information and achieving adoption in the areas of marketing, sales, and service was considered to take a minimum of 2 years. This supports the average timeframe of four years reported by [34]. Successful companies split these long-term CRM projects into manageable subprojects lasting a maximum of 6 months.

- Organizational redesign. Prior to the introduction of a CRM system all successful practices established CRM concepts for the definition of processes and organizational structures. The former includes the identification of interaction points along customer life cycles which are also established in literature (e.g. [11]) and the definition of uniform customer data and procedures across various interaction channels. This refers to the business analysis mentioned by Bose [2]. However, organizational redesign also needs to consider structural issues, i.e. to establish a centralized responsibility and authority for defining crossfunctional standards. Contrary to centralized organizations, highly decentralized organizations leave the implementation lead to country organizations and prevent conflicts with the existing culture.

- $\quad$ System architecture. Virtually all the CRM systems in the benchmarking were standard packages, while no system offered a comprehensive operational, analytical and collaborative CRM functionality. Advanced CRM companies integrated specialized systems for operational, analytical, and collaborative CRM into a best-of-breed architecture. Following the evolution path described above, mature CRM concepts also required an integration architecture for seamlessly exchanging information. A restrictive attitude was observed concerning the change requests collected among CRM users. All successful practice representatives agreed that customization of standard packages was disproportionate to the achieved benefits.

- Change management. Convincing employees of the benefits of CRM methods and systems is regarded as an important success factor reported in literature [2]. The benchmarking presents a more specific picture, since convincing call center staff proved to be not as difficult as to obtain the buy in within the sales force. Among the instruments observed were early involvement in the introduction project and the creation ment in the introduction project and the creation of incentives to use the system on a daily basis.

- Top management support. For establishing customer orientation on a corporate level (board members with customer responsibility), implementing interorganizational process and system standards, and for supporting the adoption of the CRM systems within the organization (penalizing non-use, setting an example) top management support was a key requirement. Top management sponsors also ensure that short-term setbacks in the CRM project can be overcome. This is especially important since unlike other IT projects (e.g. eProcurement projects), the introduction of CRM projects is not motivated by quantitative efficiencies but legitimized out of strategic motivations (e.g. strategic necessity, customer retention). Although this supports existing findings [13], the benchmarking emphasizes the importance of measuring whether time and budget goals have been met as well as to balance CRM investments with direct and indirect benefits.

\begin{tabular}{|c|c|c|}
\hline Benchmarks & Criteria & Critical success factors \\
\hline $\begin{array}{l}\text { Introduction } \\
\text { project }\end{array}$ & $\begin{array}{l}\text { High level of imple- } \\
\text { mentation } \\
\text { Running CRM sys- } \\
\text { tem (>6 months) }\end{array}$ & $\begin{array}{l}\text { Start with operational CRM and } \\
\text { enhance with analytical and } \\
\text { collaborative CRM } \\
\text { Rapid evaluation of CRM in- } \\
\text { formation systems } \\
\text { Medium-term projects which } \\
\text { need to be broken down in } \\
\text { manageable sub-projects }\end{array}$ \\
\hline $\begin{array}{l}\text { Organization } \\
\text { and customer } \\
\text { process }\end{array}$ & $\begin{array}{l}\text { Customer process } \\
\text { thinking } \\
\text { Analytical CRM } \\
\text { (customer segmenta- } \\
\text { tion) } \\
\text { Customer centred } \\
\text { organization struc- } \\
\text { tures }\end{array}$ & $\begin{array}{l}\text { Redesign of customer interac- } \\
\text { tion points and orientation on } \\
\text { customer process activities } \\
\text { Centralized organization unit } \\
\text { for standardization } \\
\text { Involvement of top manage- } \\
\text { ment }\end{array}$ \\
\hline $\begin{array}{l}\text { System archi- } \\
\text { tecture }\end{array}$ & $\begin{array}{l}\text { Centralized customer } \\
\text { database } \\
\text { Integration of CRM } \\
\text { applications } \\
\text { Integration of Internet } \\
\text { portals }\end{array}$ & $\begin{array}{l}\text { Select CRM system depending } \\
\text { on CRM focus } \\
\text { Use standard CRM software } \\
\text { with minimal customization } \\
\text { Integrate systems for analytical } \\
\text { and collaborative CRM with } \\
\text { operational CRM system }\end{array}$ \\
\hline Efficiency & $\begin{array}{l}\text { Quantification of } \\
\text { CRM effects } \\
\text { Availability of meas- } \\
\text { urement system }\end{array}$ & $\begin{array}{l}\text { Management of projects 'in } \\
\text { time' and 'in budget' } \\
\text { Measurement of small quantifi- } \\
\text { able benefits }\end{array}$ \\
\hline Culture & $\begin{array}{l}\text { CRM as corporate } \\
\text { philosophy } \\
\text { Availability of } \\
\text { change management }\end{array}$ & $\begin{array}{l}\text { Involve users in early stage and } \\
\text { communicate CRM goals } \\
\text { CRM should not conflict with } \\
\text { established organization culture } \\
\text { Ensure use of CRM on man- } \\
\text { agement level }\end{array}$ \\
\hline
\end{tabular}

Table 2. Summary of benchmarks, criteria and success factors 


\subsection{Outlook}

None of the benchmarked companies had a fully implemented CRM concept. Although the initial modules existed in the form of a customer database, data warehouse and portals, CRM continues to be of strategic importance and is being leveraged by technological potentials. The stated areas include:

- Communities give rise to horizontal communication between customers, businesses and suppliers. With online chat rooms, online seminars or FAQ forums [10] additional possibilities were mentioned for supporting the customer process and promoting customer retention.

- Following the Bertelsmann example, several companies are planning to integrate CRM and supply chain systems. Standard software vendors such as SAP are already positioning their CRM systems as a leading system for customer interaction and envisage various integration scenarios with other modules. The interfaces are provided by data warehouse and middleware systems.

- Mobile technologies create additional possibilities for customer contact [25]. While field sales staff already work with mobile terminals, companies are investigating which services can be offered to customers via smart devices (e.g. patient monitoring, off-board navigation).

- With predictive customer care companies try to identify customer requirements and behavior in advance. They expand their analytical CRM tools and try to analyze customers not only statically at a particular point in time but also cyclically over the complete life cycle.

- Strategies to intensify the integration of business partners (collaboration). This can mean opening up internal systems to customers on the one hand and integrating the services of external providers on the other. Consors, for example, is opening up its internal transaction system for customers.

The aim of this exploratory study was to describe the use of CRM and to identify success factors for CRM projects. It shows that CRM is still at an early stage regarding the adoption in practice as well as regarding the understanding of success factors on a detailed level. Further research is needed to derive empirically testable hypotheses as suggested by Romano [23] and to embed the success factors in a methodology which guides companies in successful CRM implementations.

\section{References}

[1] Anonymous. Enterprise Software: An Industry Finds Order in the Madness. Red Herring, 10, 16 (2000), 74-75.

[2] Bose, R. Customer Relationship Management: Key Components for IT Success. Industrial Management \& Data Systems, 102, 2 (2002), 89-97.

[3] Camp, R. Benchmarking: The Search for Industry Best Practices that Lead to Superior Performance. Milwaukee: ASQC Quality Press, 1989.

[4] Chatham, B.; Orlov, L.M.; Howard, E.; Worthen, B., and Coutts, A. The Customer Conversation. Cambridge: Forrester Research, Inc., 2000.

[5] Crego, E.T., and Schiffrin , P.D. Customer-centered Reengineering: Remapping for Total Customer Value. Burr Ridge (NY): Irwin, 1995.

[6] Fayerman, M. Customer Relationship Management. In Serban, A., M., Luan, J. (eds.), New Directions for Institutional Research, Knowledge Management: Building a Competitive Advantage in Higher Education. Chichester: John Wiley \& Sons, 2002, 57-67.

[7] Fingar, P.; Kumar, H., and Sharma, T. Enterprise ECommerce: The Software Component Breakthrough for Business-to-Business Commerce. Tampa: Meghan-Kiffer Press, 2000.

[8] Gartner. CRM in 2002: Redesign From the Customer Perspective. San Jose (CA): Gartner Group, 2001.

[9] Greenberg, P. CRM at the Speed of Light. Berkeley: Oborne /McGrawHill, 2001.

[10] Hummel, J., and Lechner, U. The Community Model of Content Management - A Case Study of the Music Industry. International Journal of Media Management, 3, 1 (2001), 4-14.

[11] Ives, B., and Learmonth, G.P. The Information System as a Competitive Weapon. Communications of the $A C M, 27,12$ (1984), 1193-1201.

[12] Keen, P.; Ballance, C.; Chan, S., and Schrump, S. Electronic Commerce Customer Relationships. Upper Saddle River (NJ): Prentice-Hall, 2000.

[13] Khirallah, K. Customer Relationship Management: How to Measure Success? Bank Accounting \& Finance, 13, 4 (2000), 21-28.

[14] Kim, H.-W.; Lee, G.-H., and Pan, S.-L. Exploring the Critical Success Factors for Customer Relationship 
Management and Electronic Customer Relationship Management Systems. In Applegate, L.; Galliers, R. and DeGross, J.I. (eds.) Proceedings $23^{\text {th }}$ International Conference on Information Systems. Barcelona: 2002, 885890.

[15] Ling, R., and Yen, D.C. Customer Relationship Management: An Analysis Framework and Implementation Strategies. Journal of Computer Information Systems, 41, 3 (2001), 81-97.

[16] Morris, G.W., and LoVerde, M.A. Consortium Surveys. American Behavioral Scientist, 36, 4 (1993), 531550 .

[17] Myers, J. Reconnecting with Customers: Building Brands and Profits in the Relationship Age. Encino (CA): Spurge, 1998.

[18] Nykamp, M. The Customer Differential: The Complete Guide to Implementing Customer Relationship Management. New York (NY): Amacom, 2001.

[19] Peppers, D., and Rogers, M. One to One B2B : Customer Development Strategies for the Business-toBusiness World. New York: Currency, 2001.

[20] Rackham, N. Rethinking the Sales Force: Redefining Selling to Create and Capture Customer Value. New York: McGraw-Hill, 1999.

[21] Radcliffe, J. Eight Building Blocks of CRM: A Framework for Success. San Jose (CA): Gartner Group, 2001 .

[22] Rigby, D.K.; Reichheld, F.F., and Schefter, P. Avoid the Four Perils of CRM. Harvard Business Review, 80, 2 (2002), 101-109.

[23] Romano, N.C. Customer Relationship Management Research: An Assessment of Sub Field Development and Maturity. In Sprague, R.H. (ed.), Proceedings 34th Hawaii International Conference on System Sciences. Los Alamitos (CA): IEEE, 2001.
[24] Ryals, L.; Knox, S., and Maklan, S. Customer Relationship Management (CRM): Building the Business Case. London: Financial Times Prentice-Hall, 2000.

[25] Sadeh, N.M. M Commerce: Technologies, Services, and Business Models. Chichester: John Wiley \& Sons, 2002.

[26] Straub, D.W.; Hoffman, D.L.; Weber, B.W., and Steinfield, C. Measuring e-Commerce in Net-Enabled Organizations: An Introduction to the Special Issue. Information Systems Research, 13, 2 (2002), 115-124.

[27] Thompson, E. CRM Is in Its Infancy in Europe. San Jose (CA): Gartner Group, 2001.

[28] Vervest, P., and Dunn, A. How to Win Customers in the Digital World. Berlin etc.: Springer, 2000.

[29] Wayland, R.E., and Cole, P.M. Customer Connections: New Strategies for Growth. Boston (MA): Harvard Business School Press, 1997.

[30] Wells, J.D.; Fuerst, W.L., and Choobineh, J. Managing Information Technology for One-to-One Customer Interaction. Information \& Management, 35, 1 (1999), 5462 .

[31] Williams, J.J., and Ramaprasad, A. A Taxonomy of Critical Success Factors. European Journal of Information Systems, 5, 4 (1996), 250-260.

[32] Wilson, H.; Daniel, E., and McDonald, M. Factors for Success in Customer Relationship Management (CRM) Systems. Journal of Marketing Management, 18, 1/2 (2002), 193-219.

[33] Winer, R.S. A Framework for Customer Relationship Management. California Management Review, 43, 4 (2001), 89-104.

[34] Yu, L. Successful Customer-Relationship Management. Sloan Management Review, 42, 4 (2001), 18-20. 